\title{
SERUM SOLUBLE VASCULAR-CELL ADHESION MOLECULE-1 (VCAM-1) IN PATIENTS WITH ACUTE AND CHRONIC LIVER DISEASES
}

\author{
MARIO PIRISI, CARLO FABRIS, EDMONDO FALLETI, GIORGIO SOARDO, PIERLUIGI \\ TONIUTTO, DANIELA VITULLI, FABIO GONANO, ETTORE BARTOLI \\ Department of Experimental and Clinical Pathology and Medicine, University of Udine, Italy.
}

\begin{abstract}
SUMMARY
Our aim was to ascertain the degree of variation of serum soluble vascular cell adhesion molecule1 (VCAM-1) concentrations according to the nature and the severity of an underlying liver disease. One-hundred forty sera collected from 123 patients ( 83 male, 40 female) with acute hepatitis $(n=14)$, mild chronic liver disease $(n=52)$ or cirrhosis $(n=57)$ of different etiologies as well as from 17 healthy blood donors ( 8 male, 9 female) were studied. Soluble VCAM-1 concentration was measured immunoenzymatically. One-way analysis of variance revealed a significant variability of the mean values of soluble VCAM- 1 among groups $(\mathrm{F}=80.02, \mathrm{p}<0.0001)$. All groups of patients had higher soluble VCAM-1 than controls; moreover, patients with acute hepatitis and patients with cirrhosis had higher soluble VCAM-1 levels than patients with mild chronic liver disease (Bonferroni's test, $\mathrm{p}<0.01$ ). These results did not change after stratification of patients according to the etiology (viral or toxic) of liver disease (two-way analysis of variance: grouping factor diagnosis, $F=60.39, p<0.0001$; grouping factor etiology, $F=1.73$, $p$ NS). Cholinesterase, total bilirubin, circulating thrombocytes and blood urea nitrogen were the independent predictors of the concentration of soluble VCAM-1. In conclusion, patients with liver disease have high serum soluble VCAM-1, which seems to reflect more the severity of impairment of liver function rather than the etiologic nature of the disease.
\end{abstract}

KEY WORDS Adhesion molecules Liver disease Cytokines.

\section{INTRODUCTION}

In the last decade, several cell-surface glycoproteins supporting the adhesion of leukocytes through their interaction with specific ligands have been identified in the vascular endothelium (Bevilacqua, 1993, Pober and Cotran, 1990). Vascular-cell adhesion molecule-1 (VCAM-1) is a $110 \mathrm{kDa}$ glycoprotein which had been found to be expressed by tumor necrosis factor (TNF)-activated endothelial cells and to bind to lymphocytes (Rice et al., 1990). It is now clear that VCAM-1 is expressed also by nonendothelial cells (Rice et al., 1991); binds monocytes, eosinophils and basophils in addition to lymphocytes (Bochner et al., 1991); and is specifically inducible by interleukin-4 (Schleimer et al., 1992). The ligand for VCAM-1 has been identified as the very late antigen-4 (VLA-4), an $\alpha 4 \beta 1$-integrin (Schwartz et cl., 1990).

Correspondence to: Mario Pirisi, M.D., Cattedra di Medicina Interna, Dipartimento di Patologia e Medicina Sperimentale e Clinica, Universit degli Studi, Piazzale Santa Maria della Misericordia 1, 33100 Udine Italy. Tel.: +39-432-559801; Fax: +39-432-42097. 
Recently, the existence of soluble forms of adhesion molecules has been demonstrated (Pigott et al., 1992, Rothlein et al., 1991). Although their role in pathophysiology remains largely unknown, their measurement may permit ready monitoring of inflammatory diseases or immunotherapy and be of help in clarifying immunopathogenetic issues (Simpson and Hayes, 1995). Soluble VCAM-1 has been found elevated in patients with alcoholic cirrhosis, in comparison to patients with alcoholic hepatitis and steatosis (Adams et al., 1994). This finding has suggested that in patients with cirrhosis local cytokine release might be shifted towards a prevalent interleukin-4 response, resulting in selective induction of VCAM-1, leading in turn to the predominantly mononuclear infiltrate observed in the cirrhotic liver.

To our knowledge, the factors associated with changes in soluble VCAM-1 concentration have not been thoroughly investigated in patients with the full spectrum of liver diseases. In the present study, our aim was to ascertain the degree of variation of soluble VCAM-1 concentrations according to the nature and the severity of the underlying liver disease. The changes in soluble VCAM-1 concentration were related to several biochemical parameters in order to examine associations with particular pathophysiologic conditions. The parameters evaluated included indices of functioning hepatic mass, of cholestasis, of hepatocellular necrosis and of the acute phase reaction.

\section{PATIENTS AND METHODS}

\section{Patients}

We studied sera collected from 123 patients ( 83 male, 40 female, age $54.3 \pm 13.9$ years, mean \pm SD, range 19-80) referred to our Institute for evaluation of suspected acute or chronic liver disease. Liver disease was considered to be due to ethanol abuse in 49 patients, to hepatitis B virus infection in 15 (in 2 of whom there was associated hepatitis $\mathrm{D}$ virus infection), to hepatitis $\mathrm{C}$ virus infection in 52, to autoimmunity (type 1 autoimmune chronic hepatitis; primary biliary cirrhosis) in 2, to idiopathic haemochromatosis in 1, while it was deemed cryptogenic in the remaining 4 patients.

Fourteen patients (12 male, 2 female, age 47.3 \pm 18.0 , range 19-72) had acute hepatitis. Fifty-two patients ( 32 male, 20 female, age 49.6 \pm 13.2 , range $21-72$ ) had mild chronic liver disease: in detail, 17 had liver steatosis and 35 had chronic hepatitis. Fiftyseven patients ( 39 male, 18 female, age $60.4 \pm 10.8$, range $33-80$ ) had cirrhosis, which was complicated by hepatocellular carcinoma in 27 patients. Acute hepatitis was diagnosed on clinical grounds. Diagnoses of chronic hepatitis and liver steatosis were all established by histopathological evaluation of liver specimens obtained by percutaneous liver biopsy. Cirrhosis was diagnosed clinically on the basis of evidence of portal hypertension, ascites, hypoalbuminemia, hypergammaglobulinemia and confirmed histologically in the majority of patients. Hepatocellular carcinoma was diagnosed in the presence of raised $(>400 \mu \mathrm{g} / \mathrm{L})$ serum levels of alpha-1-fetoprotein and/or suggestive radiological imaging; it was always confirmed histologically or at necropsy.

Seventeen subjects ( 8 male, 9 female, age 49.6 14.7 , range $25-73$ ) were healthy blood donors and were used as controls. The study was conducted in strict observance of the principles of the Declaration of Helsinki.

Biochemical determinations. Circulating VCAM-1 was measured by an enzyme immunoassay (Soluble VCAM-1 ELISA Kit, British Bio-technology Products Ltd, 
Abingdon, UK). This test has a sensitivity $<2.0 \mu \mathrm{g} / \mathrm{L}$, with intra-assay coefficients of variation ranging from 4.3 to $5.9 \%$ and inter-assay coefficients ranging from 8.5 to $10.2 \%$. Reference mean value had been determined to be $553 \mu \mathrm{g} / \mathrm{L}$ ( $\pm 2 \mathrm{SD}$ range 234 872 ) in a panel of 105 apparently normal donors.

\section{Statistical analysis}

We tested normality of data performing Shapiro and Wilk's W statistic. Parameters demonstrating a significant departure from normal distribution were logarithmically transformed prior to further statistical analysis. To test the existence of differences among the groups with regard to categorical variables (such as normal or pathological circulating VCAM-1 concentration), Pearson chi-square tests were performed. One-way and two-way analysis of variance were applied to detect differences in the population means with regard to circulating VCAM-1 concentrations. Bonferroni's test was used for multiple comparisons among the groups. Simple regression analysis was utilized to correlate circulating VCAM-1 variations with variations in several biochemical parameters; those which were significant on univariate analysis were tested as independent predictors of soluble VCAM-1 using a stepwise approach. All statistical tests were performed by means of the BMDP statistical software package (Dixon, 1992).

\section{RESULTS}

Figure 1 presents the scatterplot of individual values of circulating VCAM-1, according to the diagnostic categories of patients. One-way analysis of variance demonstrated the existence of a significant variability of the mean values of circulating VCAM1 among groups $(\mathrm{F}=80.02, \mathrm{p}<0.0001)$. All groups of patients had higher circulating VCAM-1 than controls; moreover, patients with acute hepatitis and patients with cirrhosis had higher VCAM-1 levels than patients with mild chronic liver disease (Bonferroni's test for pairwise comparisons, $\mathrm{p}<0.01$ ). These results did not change after stratification of patients according to the etiology (viral; toxic) of liver disease (two-way analysis of variance: grouping factor diagnosis, $\mathrm{F}=60.39$, $\mathrm{p}<0.0001$; grouping factor etiology, $\mathrm{F}=1.73$, $\mathrm{p}$ NS). A concentration of soluble VCAM-1 in the pathological range (i.e., higher than 2 SD above the reference mean value) was detected in 14/14 patients with acute hepatitis, $27 / 52$ patients with mild chronic liver disease and 55/57 patients with cirrhosis (Pearson chi-square 35.97, $\mathrm{p}<0.0001$ ).

The results of univariate regression analysis are presented in Table 1 . The circulating form of VCAM-1 was shown to correlate positively with serum markers of cholestasis, of hepatocellular necrosis and of the acute phase reaction and inversely with indices of functioning hepatic mass, with haematocrit and with the number of circulating thrombocytes.

Multivariate analysis is presented in Table 2. In our population of patients cholinesterase, total bilirubin, circulating thrombocytes and blood urea nitrogen were the independent predictors of the concentration of circulating VCAM-1.

\section{DISCUSSION}

Our data indicate that soluble VCAM-1 concentration is increased in patients with liver disease, in comparison to control subjects. The highest levels occur in patients with 


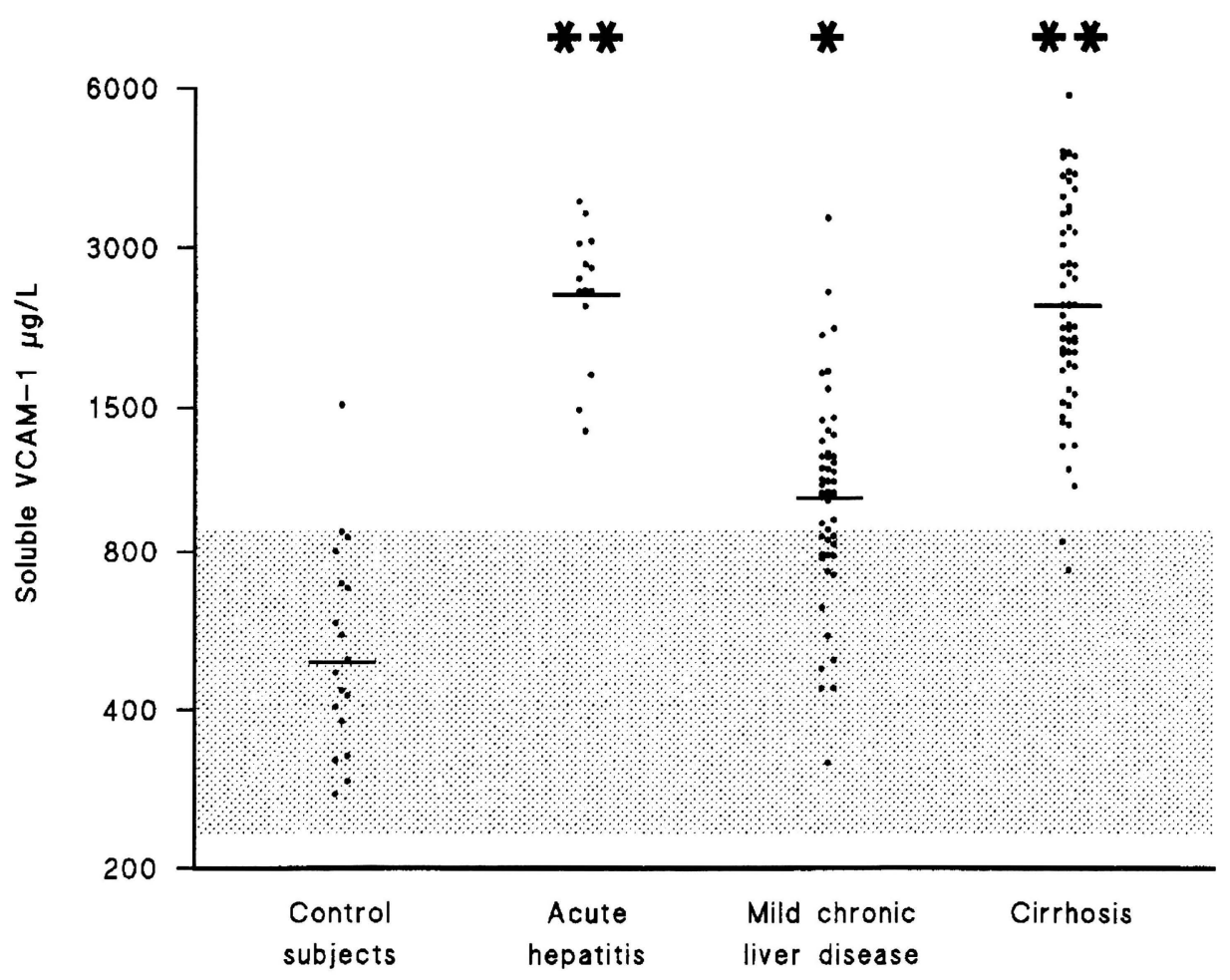

Figure 1. Scatterplot of the individual values of soluble VCAM-1 according to the diagnostic categories of the studied population. A line indicates the geometric mean value in each group. A shaded area indicates the reference range of normality (mean reference value $\pm 2 \mathrm{SD}$ ). Bonferroni's test for pairwise comparisons: **, $\mathrm{p}<0.01$ with respect to control subjects and to patients with mild chronic liver disease; *, $\mathrm{p}<0.01$ with respect to control subjects.

acute hepatitis and in patients with advanced chronic liver disease, with lower levels measured in patients with only mild impairment of liver function. While the severity of liver disease matters, soluble VCAM-1 does not seem to be influenced by the etiology (toxic or viral) of the disease. This is in agreement with data showing that the expression of vascular adhesion molecules in liver tissue varies according to the type of liver disease but not according to its cause (Volpes et al., 1992), and it is interesting in view of the different kind of infiltrate predominantly seen in the liver according to cause of disease. In acute and chronic viral infection of the liver, a mononuclear infiltrate is seen. Alcoholic liver damage leads initially to extravasation of neutrophils in the liver parenchyma, while a predominantly mononuclear infiltrate is observed in alcoholic cirrhosis. The expression of VCAM-1 mediates the adhesion of mononuclear blood cells, but not neutrophils, to the vascular endothelium (Shimizu et al., 1990): thus, it would be plausible to expect an increase concentration of soluble VCAM-1 mainly in those liver diseases characterized by a mononuclear infiltrate. To be able to rely on simple serum measurements to discriminate between different etiologic possibilities (for example, when acute alcoholic hepatitis is concerned) is sometimes 
Table 1. Univariate linear regression analysis (dependent variable: soluble VCAM-1). Variables logarithmically transformed (owing to a significant departure from normal distribution) are indicated by an asterisk.

\begin{tabular}{|c|c|c|}
\hline Variable & $\mathrm{r}$ & $\mathrm{p}$ \\
\hline Hematocrit* & -0.418 & $<0.001$ \\
\hline White blood cells* & 0.014 & NS \\
\hline Circulating thrombocytes* & -0.602 & $<0.001$ \\
\hline C-reactive protein* & 0.403 & $<0.001$ \\
\hline Erythrocyte sedimentation rate* & 0.451 & $<0.001$ \\
\hline Alpha-1-antitrypsin* & 0.467 & $<0.001$ \\
\hline Aspartate aminotransferase ${ }^{*}$ & 0.511 & $<0.001$ \\
\hline Total bilirubin* & 0.665 & $<0.001$ \\
\hline$\gamma$-glutamyltranspeptidase* & 0.348 & $<0.001$ \\
\hline Alkaline phosphatase* & 0.454 & $<0.001$ \\
\hline Albumin & -0.617 & $<0.001$ \\
\hline Cholinesterase & -0.685 & $<0.001$ \\
\hline Blood Urea Nitrogen* & 0.233 & $<0.01$ \\
\hline
\end{tabular}

Table 2. - Summary of the results of stepwise multiple regression analysis (dependent variable: soluble VCAM-1). Variables logarithmically transformed (owing to a significant departure from normal distribution) are indicated by an asterisk.

\begin{tabular}{llcc}
\hline Step & Variable & $\mathrm{r}$ & F to enter \\
\hline 1 & Cholinesterase & 0.706 & 89.2 \\
2 & Bilirubin* & 0.776 & 23.4 \\
3 & Circulating thrombocytes* & 0.804 & 10.9 \\
4 & Blood Urea Nitrogen* & 0.816 & 5.1 \\
\hline
\end{tabular}

desirable. However, our data, indicating a large overlap in soluble VCAM-1 concentration among patients with liver diseases of different etiology, do not support the hypothesis that we might be able to predict by soluble VCAM-1 alone which type of morphologic changes is to be expected in the liver. In fact, in agreement with the currently accepted multi-step model of leukocyte extravasation (Butcher, 1991), the presence of a certain inflammatory infiltrate does not allow direct conclusions to be drawn about the expression of adhesion molecules on the inflamed endothelium, and vice versa.

The results of univariate and multivariate regression analysis further emphasize that the severity of the deranged liver function, rather than the specific pattern of injury, seems to be associated with the elevation of soluble VCAM-1. Serum concentrations of cholinesterase, bilirubin and blood urea nitrogen, together with the platelet count, are independent predictors of soluble VCAM-1 concentration while conventional markers 
of inflammation (erythrocyte sedimentation rate, C-reactive protein, leukocyte count) are not.

These results are very similar to those already published by our group with regard to the concentration of soluble intercellular adhesion molecule-1 (ICAM-1) in patients with liver disease (Pirisi et al., 1994). Indeed, the soluble forms of both VCAM-1 and ICAM1 share in patients with liver disease a strict correlation with markers of cholestasis and of a reduced functioning hepatic mass. This raises the possibility that their concentration in serum might increase mainly because of an impairment of the excretory functions of the patients (Lim et al., 1994, Zöhrens et al., 1993).

For the association between soluble VCAM-1 and the platelet count there is not an easy explanation. The correlation between these two parameters was stronger in the group of patients with mild rather than advanced chronic liver disease (data not shown). It might reflect trapping of cells by an activated reticulo-endothelial cell system, of which soluble VCAM-1 is a marker; or, the same cytokines leading to expression of VCAM1 and release of its soluble form might determine a slight suppression of marrow production of thrombocytes. The serum concentration of interleukin- $1 \beta$, which acts synergistically with interleukin-4 to induce VCAM-1 expression in the endothelium (Masinovsky et al., 1992), has an inverse correlation with the platelet count (Tilg et al., 1992). However, in patients with cirrhosis, where pooling of thrombocytes in an enlarged spleen is recognized as the major mechanism of thrombocytopenia, the expression of adhesion molecules might be a less important determinant of the platelet count.

It is unclear whether the soluble form of VCAM-1 might interfere with the adhesion of leukocytes to endothelial cells. Preliminary evidence seems to suggest that soluble VCAM-1 is neither chemotactic nor proadhesive, in contrast to soluble E-selectin (Adams et al., 1994). It is conceivable that in fact soluble VCAM-1 might compete for the same ligand recognized by the membrane-bound form, operating a negative feedback on the ability of leukocytes to reach the site of inflammation. If this were true, high soluble VCAM-1 levels might contribute to the impairment of immune surveillance observed in patients with advanced chronic liver disease.

\section{REFERENCES}

Adams, D.H., Burra, P., Hubscher, S.G., Elias, E., Newman, W. (1994). Endothelial activation and circulating vascular adhesion molecules in alcoholic liver disease. Hepatology, 19, 588-594.

Bevilacqua, M.P. (1993). Endothelial-leukocyte adhesion molecules. Annu. Rev. Immunol., 11, 767-804.

Bochner, B.S., Luscinskas, F.W., Gimbrone, M.A. Jr, Newman, W., Sterbinsky, S.A., DerseAnthony, C.P., Klunk, D., Schleimer, R.P. (1991). Adhesion of human basophils, eosinophils, and neutrophils to interleukin 1-activated human vascular endothelial cells: contributions of endothelial cell adhesion molecules. J. Exp. Med., 173, 1553-1556.

Butcher, E.C. (1991). Leukocyte-endothelial cell recognition: three (or more) steps to specificity and diversity. Cell, 67, 1033-1037.

Dixon, W.J. (1992). BMDP statistical software manual. Berkeley: University of California Press.

Lim, A.G., Jazrawi, R.P., Ahmed, H.A., Levy, J.H., Zuin, M., Douds, A.C., Maxwell, J.D., Northfield, T.C. (1994). Soluble intercellular adhesion molecule-1 in primary biliary cirrhosis: relationship with disease stage, immune activity and cholestasis. Hepatology, 20, 882-888.

Masinovsky, B., Urdal, D., Gallatin, W.M. (1992). Il-4 acts synergistically with Il-1 beta to promote lymphocyte adhesion to microvascular endothelium by induction of vascular cell 
adhesion molecule-1. J. Immunol., 145, 2286-2895.

Pigott, R., Dillon, L.P., Hemingway, I.H., Gearing, A.J.H. (1992). Soluble forms of E-selectin, ICAM-1 and VCAM- 1 are present in the supernatant of cytokine activated cultured endothelial cells. Biochem. Biophys. Res. Commun., 187, 584-589.

Pirisi, M., Falleti, E., Fabris, C., Soardo, G., Toniutto, P., Vitulli, D., Pezzetta, F., Bortolotti, N., Gonano, F., Bartoli, E. (1994). Circulating intercellular adhesion molecule-1 (cICAM-1) concentration in liver disease: relationship with cholestasis and functioning hepatic mass. Am. J. Clin. Pathol., 102, 600-604.

Pober, J.S., Cotran, R.S. (1990). Cytokines and endothelial cell biology. Physiol. Rev., 70, $427-$ 451.

Rice, G.E., Munro, J.M., Bevilacqua, M.P. (1990). Inducible cell adhesion molecule 110 (INCAM-110) is an endothelial receptor for lymphocytes. A CD11/CD18-independent adhesion mechanism. J. Exp. Med., 171, 1369-1374.

Rice, G.E., Munro, J.M., Corless, C., Bevilacqua, M.P. (1991). Vascular and nonvascular expression of INCAM-110. A target for mononuclear leukocyte adhesion in normal and inflamed human tissues. Am. J. Pathol., 138, 385-393.

Rothlein, R., Mainolfi, E.A., Czajkowski, M., Marlin, S.D. (1991). A form of circulating ICAM1 in human serum. J. Immunol., 147, 3788-3793.

Schleimer, R.P., Sterbinsky, S.A., Kaiser, J., Bickell, C.A., Klunk, D.A., Tomioka, K., Newman, W., Luscinskas, F.W., Gimbrone, M.A. Jr, McIntye, B.W., Bochner, B.S. (1992). IL-4 induces adherence of human eosinophils and basophils but not neutrophils to endothelium. J. Immunol., 148, 1086-1092.

Schwartz, B.R., Wayner, E.A., Carlos, T.M., Ochs, H.D., Harlan, J.M. (1990). Identification of surface proteins mediating adherence of CD11/CD18-deficient lymphoblastoid cells to cultured human endothelium. J. Clin. Invest., 85, 2019-2022.

Shimizu, Y., van Seventer, G.A., Horgan, K.J., Shaw, S. (1990). Regulated expression and function of three VLA ( $\beta 1$ ) integrin receptors on T cells. Nature, 345, 250-253.

Simpson, K.J. and Hayes, P.C. (1995). Soluble adhesion molecules in immune mediated liver disease. Gut, 36, 806-808.

Tilg, H., Wilmer. A.. Vogel, W., Herold, M., Nölchen, B., Judmaier, G., Huber, C. (1992). Serum levels of cytokines in chronic liver diseases. Gastroenterology, 103, 264-274.

Volpes, R., van den Oord. J.J., Desmet, V.J. (1992). Vascular adhesion molecules in acute and chronic liver inflammation. Hepatology, 15, 269-275.

Zöhrens, G., Armbrust. T.. Polzien, F., Ramadori, G. (1993). ICAM-1 serum concentration in cholestasis. Indications for a biliary elimination. J. Hepatol., 18, S43 (Abstract). 


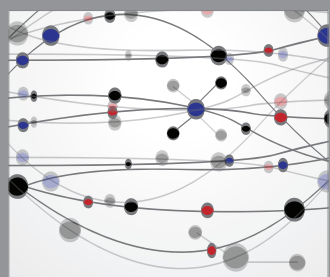

The Scientific World Journal
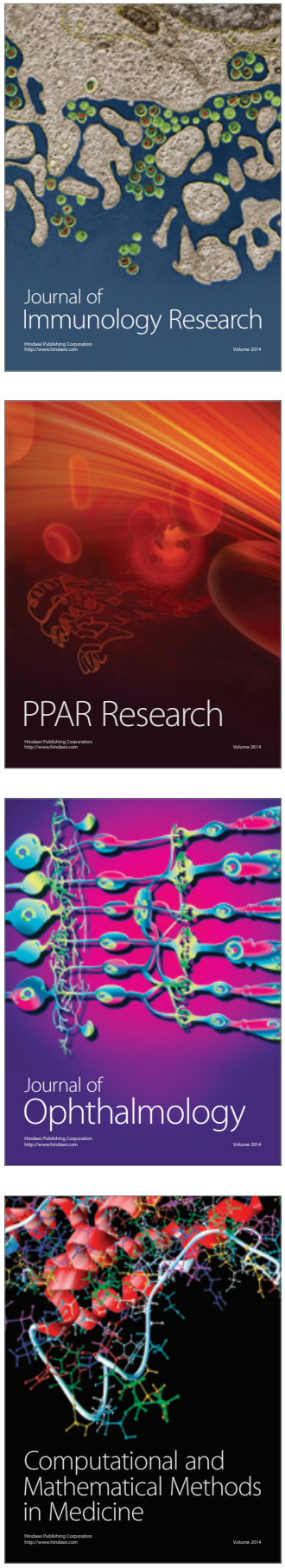

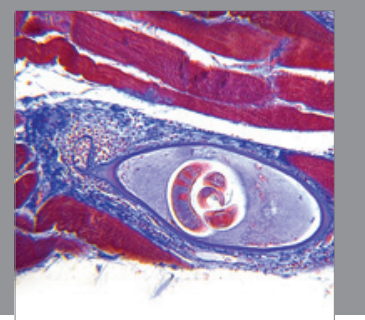

Gastroenterology

Research and Practice
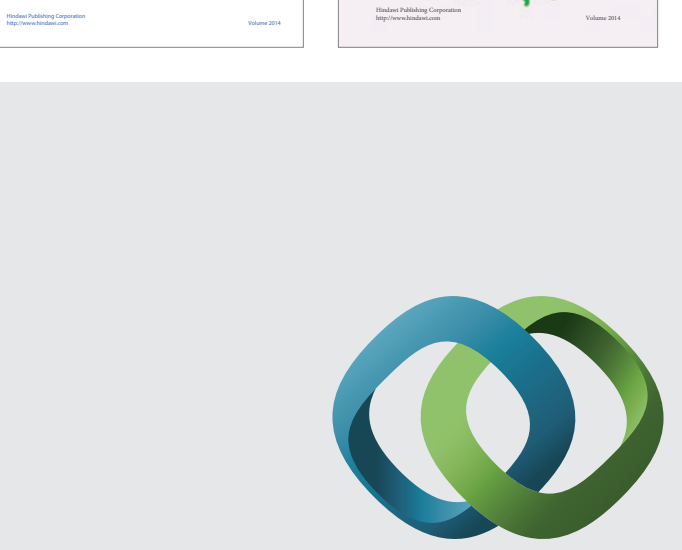

\section{Hindawi}

Submit your manuscripts at

http://www.hindawi.com
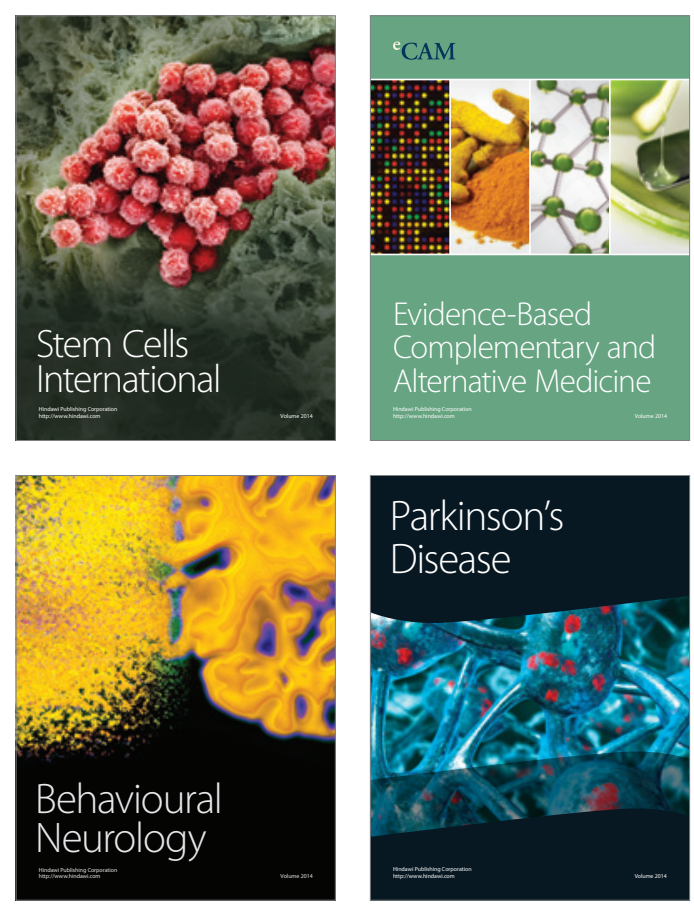

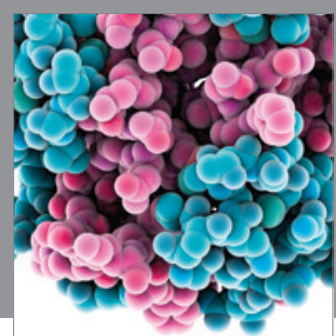

Journal of
Diabetes Research

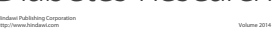

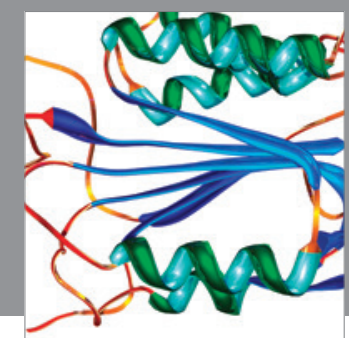

Disease Markers
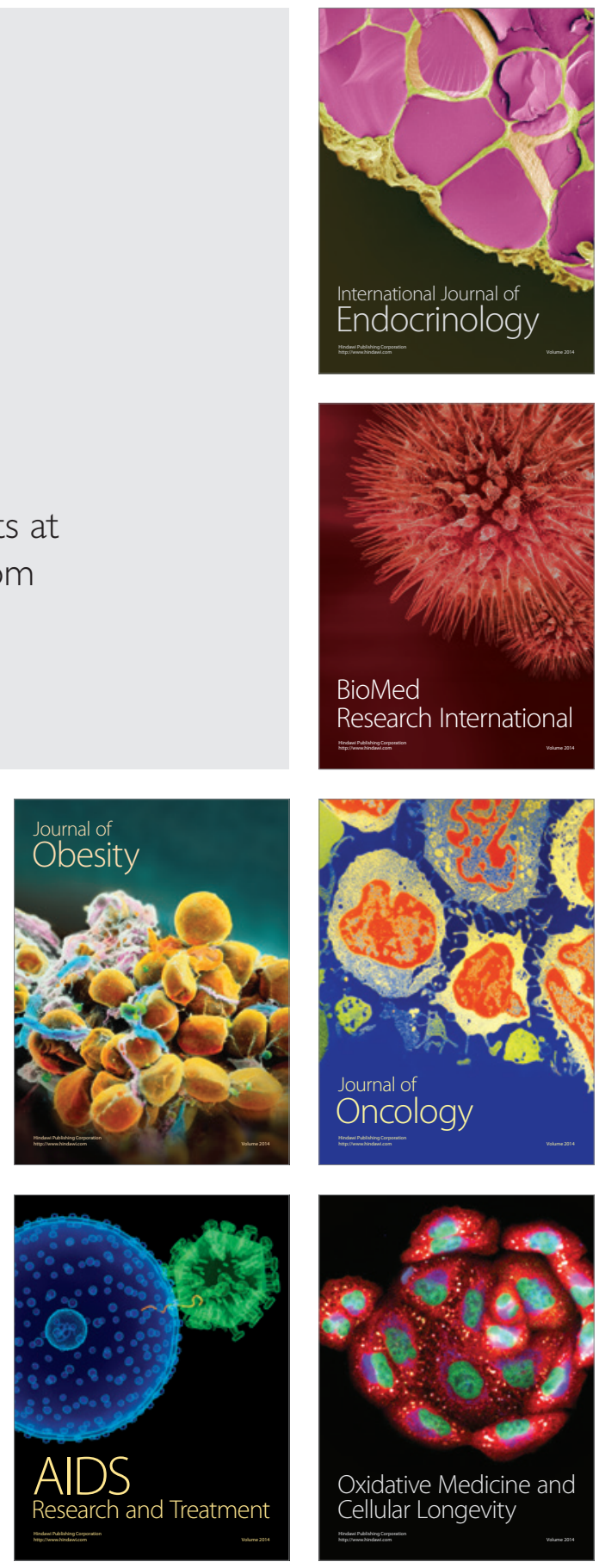